\title{
WHAT WOMEN STUDENTS WANT THEIR INSTITUTIONS TO DO TO MAKE ENGINEERING EDUCATION MORE INCLUSIVE AND LESS "CHILLY"
}

\author{
Cori Hanson \\ Ontario Institute for Studies in Education \& Faculty of Applied Science \& Engineering, \\ University of Toronto \\ cori.hanson@utoronto.ca
}

\begin{abstract}
It has been over 30 years since science and engineering classrooms were first described as "chilly" environments for women. Since then many engineering programs in Ontario have worked to diversify their student populations with a particular focus on recruiting more women into engineering education. Despite the increase in the number of women enrolled in engineering education, incidents of sexism and microaggressions based on sexual orientation and race continue to be experienced by women in these programs.

In many engineering faculties in Ontario work on equity, diversity and inclusion is still fairly new. Members of the community who are marginalized need to be consulted in order for this work to be impactful on their experience. This paper uses an intersectional framework to present preliminary results on what women studying in undergraduate engineering programs believe their universities could do to make engineering education more inclusive. This paper argues that women students in engineering are still in search of a community. Our women students want more representation of women in engineering, further education and awareness of equity issues, acknowledgement of their experiences and opportunities to connect with other women in engineering.
\end{abstract}

Keywords: equity, diversity, inclusion, intersectionality, women in engineering, student experience

\section{INTRODUCTION}

In 1996, Sandler, Silverberg and Hall coined the term "chilly" to describe the climate for women studying science, technology, engineering and mathematics [1]. At the time this was attributed the small number of women studying in these fields. Since then many engineering programs and Faculties have worked to reach gender parity in engineering education. From 1991 to 2017, Canada saw an increase in women enrolled in engineering programs with $21.8 \%$ women reported being enrolled in undergraduate engineering programs in 2017 with Ontario women student enrolment slightly above the national average [2]. Some Ontario institutions have increased the number of women enrolled in their undergraduate engineering programs to over
$30 \%$. While these enrolment numbers are an improvement, it is worth noting that they are still lower than the participation rate of women overall in university-level education, which in Canada was up to $64 \%$ by 2007 [3].

As a student affairs professional working in engineering education I continue to witness and hear about experiences of women students and faculty that are inequitable and discriminatory. Like many of my colleagues, I was hopeful that increasing the number of women in engineering education would make our campuses more inclusive but progress towards equity and inclusivity for women and other marginalized students in these programs continues to be slow. Often I have discussion with students, staff and faculty who are unsure of what steps to take to make their classrooms and campuses more inclusive. To support this desire for progress and address these uncertainties, this research asked women students what we can do as educators to support them while they study engineering.

Not all voices and identities of women are represented in this paper. While all of the participants identified as women none of the participants identified as transwomen, genderqueer or non-binary. This is a limitation to this research. More research is needed to understand the experiences and needs of transwomen and non-binary people in engineering education.

I hope this paper will give further insights into what actions we can all make and systemic changes we can continue implement and advocate for to make our campuses more equitable and inclusive for more women.

\subsection{Women in engineering education}

There is a history of sexism and misogyny (e.g. sexist course material, harassment from colleagues and professors and unequitable pedagogy etc.) in engineering classrooms [4], [5], [6]. In 2001, 16\% of women enrolled in engineering at the University of Calgary reported they had been discriminated against because of their gender and $25 \%$ women in engineering programs know others who had experienced gender-based discriminated, compared to $4 \%$ and $17 \%$ for men respectively [5]. When women in engineering education interact with sexist men, they experience stereotype threat which can undermine their 
performance [6]. This means that women who detect sexist cues in men's behaviour are at risk of being viewed as a negative gender stereotype [6]. Interactions like this can also create distrust, uncertainty and feelings of being devalued [6].

Research on women in engineering education has looked to better understand implicit barriers for inclusion and persistence, such as self-efficacy, confidence, selfexpectations and identity development [7], [8]. When explicit barriers are explored the focus here is usually on access and academic preparation, [4], [9], [10]. One Canadian study that did consider interpersonal relationships tested two interventions to support women students in engineering programs [11]. The interventions did have an impact, one helped women develop their engineering identity and the other helped women connect to their peers who were mostly men [11]. Both of these interventions where focused on changing the behaviours and attitudes of the women enrolled in engineering programs, neither considered systemic changes institutions could make or possible changes in behaviour or attitude the men in these programs could make to be more inclusive.

In general, there has been little recent literature published on sexism and discrimination of women in engineering education in Canada and this literature rarely indicates what systemic changes need to be made.

\subsection{LGBTQ students and racialized students in engineering education}

Despite the way we often talk about women in engineering they are not a homogeneous group. For example, lesbian, gay, bisexual, transgender, and queer (LGBTQ) women and racialized women, i.e. women who belong to ethno-racial groups that are categorized, seen as inferior, and marginalized [12], are even further marginalized and underrepresented in engineering education. Unlike binary-gender, race and sexual orientation demographic data is not commonly collected by Ontario post-secondary institutions, so within these communities which communities and identities are underrepresented and by what degree is not explicitly known. However, Black feminists have shown that previous activist movements have mainly benefitted White, heterosexual, able-bodied, cis-women when the focus has been equity for all women [13], [14], [15], [16]. Our peers in the United States (US) collect more demographic information on their university students than we do in Canada, so we can look to them for insights into the experiences of LGBTQ and racialized students.

Studies in the US have found that LGBTQ students are marginalized in engineering programs and that this is experienced as isolation and devaluation [17], [18]. Students perceive being gay as a potential threat to their sense of belonging in engineering [18]. In addition, LGBTQ engineering students are significantly more likely to report issues with stress, sleep and anxiety than non-
LGBTQ students, in part because of the extra energy required to compartmentalize their lives at school [17]. As a result, LGBTQ engineering students do not often selfidentify, nor are they open with their sexual orientation with their peers or professors [17]. In one study on LGBTQ students in engineering, Asian students were more likely to feel exhausted from compartmentalizing their sexuality than students of other races. In the same study, Black and Asian students were more likely to report feelings of nervousness than White students [17].

The literature also shows that racialized students have different experiences than their White peers in STEM programs, particularly when these programs and institutions are predominantly White. Studies have found that Black students in STEM programs feel less supported by faculty at predominantly White institutions [19]. While, Native American students struggle to find a sense of belonging in their predominately White programs resulting in attrition despite the strong personal motivation to acquire knowledge and skills that they could bring back to their communities [20].

In post-secondary education broadly, researchers have found that racialized students experience harmful microaggressions [21], [22], [23]. Microaggressions continually wear on racialized people by reminding them why they are considered different than their White peers [24]. Microaggressions occur and have impact even when the perpetrator is unaware of them or has good intentions [22]. Racialized people can still be impacted by microaggressions even if they do not fully process or notice or acknowledge that a microaggression towards them has occurred [22]. Overtime, microaggressions can lower confidence, decrease one's sense of belonging, cause anger and create environments where it is difficult or impossible for racialized students to learn [22].

Racialized women in STEM programs are more likely to experience microaggressions than racialized men and White women [23], [7]. For example, one study on the climate of engineering education reported that Black women students were more likely to report a negative climate in their engineering department than their White peers [7].

Another study found that Black women in engineering programs rated their communications skills lower than White women in the same programs [25]. It was also found that that Asian men, like other racialized men, rated their technical and professional skills lower than White men even though Asian men and White men are both majority groups in engineering education [23]. Despite sometimes being a majority group in engineering, Asian men still had low self-efficacy and confidence in their abilities, and this could be a result in their experiences as racialized students in a traditionally White institution and program.

We need considerably more research on marginalized student experiences in engineering education, particularly from a Canadian context. Yet even this brief review the 
literature in the US shows that the experiences of engineering students broadly is impacted by their identity and this is likely also the case in Canada. In particular, the research shows that this relationship between identity and inclusion is complex and intersectional.

\subsection{Theoretical framework - Intersectionality}

Intersectionality recognizes that a person's identity is fluid and is dependent on contextual influences such as past experiences, sociocultural conditions and current experiences. Therefore an individual's identity cannot be fully understood simply by considering the various parts of their identity separately [26], [27]. Each intersection of identity is unique meaning that you cannot presume to understand the experiences of someone based on the experiences of others who share one more aspect of their identity. For example, you cannot understand the experiences of Black women from research on the experiences of White women and Black men. An intersectional framework acknowledges the different dynamics of power, privilege and oppression created by unique intersections of identity [26].

Using an intersectional framework allows for a more robust understanding of the complexity of equity and inclusion issues in engineering education and the barriers women students face to finding community on campus. This research is intersectional and considers more than one dimension of identity of the engineering students who participated and does not assume that all dimensions of difference play equal roles in all contexts.

\subsection{Researcher's positionality}

In addition to the theoretical framework used for this paper, I bring my own biases and positionality to this work. I am a White, heterosexual, able bodied, educated, ciswomen who lives with anxiety. Because many aspects of my identity align with cultural norms in Canada I have many privileges here as a settler on this land, where I have always lived, and am now conducting this work. I recognize that the experiences I am discussing here are not my own. I am not an engineer, nor have I ever been an engineering student. My analysis is through the lens of a critical scholar, who's research areas include engineering education, equity, diversity and inclusion, and the student experience, as well as my experiences working in postsecondary education as a student affairs professional.

\subsection{Significance}

As diversity in engineering programs changes, institutions and educators interested in creating more equitable and inclusive experiences for their students are not always sure how to do this. This paper shares ideas from current women engineering students on what they want their universities to do to better support themselves and their peers. This paper uses an intersectional framework to consider these ideas and the needs of women students to better understand the complexity of creating inclusive spaces in engineering education.

\section{METHODOLOGY}

\subsection{Data collection \& analysis}

Data was collected through an online survey. This survey was part of a larger doctoral dissertation exploring the impact of whiteness and maleness on student experiences and inclusion in engineering education. This paper presents the results and analyses of the data collected by one qualitative open-ended survey question, "What could your university do to better support students who are the same race and/or gender as you?" Respondents were not required to answer all of the survey questions and could opt to not answer this question. Of the total respondents $(\mathrm{N}=50), 15$ women answered this question. This study used thematic analysis and inductive coding. From this analysis of the 15 long answer text responses two themes emerged: 1) representation and 2) education and awareness, and four universal human needs were identified: 1) to be included, 2) to be acknowledged, 3) to be listened to, and 4) to be supported.

\subsection{Participants}

Participants were recruited by email and social media to complete a survey on their experiences in engineering education in Ontario. Most recruitment was done through outreach to engineering student clubs and engineering student societies, and two engineering Faculties promoted the survey through their student e-newsletters. Students currently enrolled in undergraduate engineering programs at a university in Ontario were eligible to participate. In total 50 engineering students completed the survey.

The following summarizes the demographic data for the 15 participants who provided the survey responses considered in this paper. They were all enrolled as engineering students in accredited undergraduate engineering programs in Ontario during the 2019-2020 academic year. They came from five universities and nine engineering disciplines. The names of their universities have not been included to ensure confidentiality and privacy are maintained. All 15 participants identified as women. None of the participants identified as transwomen, genderqueer, or non-binary. Table 1 summarizes how these women identified by race and sexual orientation. All but one participant was a domestic student, one participant was an international student. All of these participants were traditionally aged university students (i.e. 18-21 years old). Three of the participants indicated they had an invisible disability, the other 12 participants said they did not have a disability. 
Table 1. Summary of participants by self-identified race and sexual orientation.

\begin{tabular}{|l|c|c|c|c|c|c|}
\hline & Bisexual & Lesbian & $\begin{array}{c}\text { Not sure/ } \\
\text { questioning }\end{array}$ & Pansexual & Heterosexual & Total \\
\hline Black & 1 & 0 & 0 & 0 & 1 & 2 \\
\hline East Asian & 0 & 0 & 0 & 0 & 1 & 1 \\
\hline Southeast Asian & 0 & 0 & 0 & 0 & 3 & 3 \\
\hline South Asian & 2 & 0 & 0 & 0 & 0 & 2 \\
\hline White & 1 & 1 & 2 & 1 & 2 & 7 \\
\hline Total & 4 & 1 & 2 & 1 & 7 & 15 \\
\hline
\end{tabular}

\subsection{Ethical Considerations}

This research approved by the University of Toronto Research Ethics Board. All participants provided consent to be included in this study and were given the option to decline to answer any question in the survey or withdraw their participation at any time. Privacy and confidentiality of participant identity has been maintained throughout data collection, analysis and publication process.

\section{RESULTS \& DISCUSSION}

\subsection{Intersectional representation of women in engineering}

So much progress has been made in engineering education to recruit more women as students and faculty members. With some universities in Ontario now consistently welcoming first-year engineering classes of $30-40 \%$ women each year. This has been a needed and important step forward. However, this does not mean that all women are being represented. This broad focus on the recruitment of women in engineering has not always or often been intersectional and there is still work to be done.

Five of the fifteen respondents in this study indicated they would like more students and faculty who share their identities in their programs. Representation becomes a more complex issue when considered through an intersectional framework. In particular when we look at the intersections of gender with race or engineering discipline.

"Outreach; try to accommodatelattract more students of this race to the program." - A Black, heterosexual, women student in civil engineering

If this student still does not see many Black students in their program, it is likely that they also do not see many or any Black women professors, instructors or teaching assistants. This becomes an even more complex problem we consider the likelihood of a Black, LGBTQ student being able to learn with and from people who share multiple aspects of their identities.

White women also still feel underrepresented in certain engineering disciplines, despite being likely more represented in engineering education than some or all of their racialized peers.

"Encourage women to go into the more male dominated streams, not just engineering overall." - A White, LGBTQ, women student in electrical engineering

"The university could put more effort into attracting more females to the program so that being female no longer stands out or seems abnormal." - A White, heterosexual, women student in aerospace engineering

Recruiting women into engineering programs broadly has worked to increase the overall participation rates. However, in some disciplines women continue to be less represented and less visible and our students have noticed.

"It's tricky. I would say hire more female profs, but I also understand that there are still less females than males in the field, so the supply is smaller." - A White, LGBTQ, woman student in computer engineering

"Hire more diverse staff to better reflect a student population that is becoming more diverse." - A South Asian, LGBTQ, woman student in computer engineering

Women students also want to be taught by women. White and racialized women students want to see themselves represented in the people who work in engineering education not just the students who study there. They are aware of why the likelihood of them being a taught by a women in their discipline is low, but they want this to change.

\subsection{Education and awareness}

Eight of the fifteen students believe that their institution could do more to increase awareness and do more to educate the men in engineering on the issues of sexism and racism in engineering education.

"Educate male engineering students about inclusivity with other gender." - A Southeast Asian, heterosexual, woman student in mechatronics engineering

"Connect us to each other better, talk about phenomena 
that affect us not only with us who experience it but with other students and the faculty who perpetrate it" - A Black, $L G B T Q$, woman student in civil engineering

Women students want shared responsibility in making engineering education more inclusive. They feel it is in part their universities responsibility to help educate and connect them with their peers to eliminate sexism. They want the men they are studying with and being taught by to do their part to make engineering more inclusive by learning about the issues they are facing as women. It is likely that they hope that education and conversations across genders will help motivate men to change sexist behaviours that are detrimental to women being able to learn in engineering.

"I hope they reached out more to us and listen to what we have to say in private. There's a lot of amazing ideas we have but we do feel that as a minority we have nowhere to share it so it leads to us being quiet." - Southeast Asian, heterosexual, woman student in engineering science

Women students want to be part of the conversation around gender equity, diversity and inclusion. They are experiencing the change in diversity on campuses and do not always feel empowered to speak up on what could help improve their experience.

"Much better education about what constitutes a mental illness. ... There needs to be more of an understanding around how mental illness differs from regular wellbeing, especially less common disorders ... because many people are miseducated and those incorrect notions hurt people with those conditions." - A White, LGBTQ, woman student in systems engineering

The desire for education was not limited to more awareness around gender issues. Living with an invisible disability, like mental illness, a visible disability or another form of being neuroatypical all need the be considered when using an intersectional lens to discuss indent and experience. These are all aspects of identity that can cause isolation, discrimination, harassment and oppression. The way that students experience mental illness or other disabilities can be different depending on different intersections of the dimensions of their identity. Depending on the context where an individual is experiencing mental illness it can be experienced in different ways. The research on LGBTQ students and racialized students shows that existing with these identities in traditionally White, cismale spaces, like engineering, impact mental health and wellbeing often resulting in feelings of loneliness and isolation [17], [18], [24].

Again, consider being a Black, LGBTQ woman in an engineering discipline where most other students are White, heterosexual, cis-men. The research shows that she is likely to experience microaggressions because of her race, gender and sexual orientation. Now consider that if this student also has a mental illness such as anxiety, depression or bipolar disorder etc. this would likely impact her ability to cope with continually being reminded that she is different than her peers.

"Provide program-focused opportunities to talk about things that we find difficult. Women in Eng for the whole faculty is great, but it would be nice to connect with both students and staff in my program that identify as female to discuss issues." - A White, LGBTQ, woman student in systems engineering

Awareness is not only about the education of others; it is also about women in engineering better understanding the similarities and differences of their shared experiences.

Again we can learn from past Black feminist movements where change and empowerment was cultivated in shared spaces that allowed women to learn about each other's experience that could be both similar and different from their own [16]. These spaces and communities have empowered women to fight for equity and systemic changes. These connections allow women to determine where the barriers are from sharing their experiences and work together to support each other and implement change [16]. Providing spaces for women to connect in engineering programs can empower and supporting women while providing needed safe spaces for community building.

"Do more to stand up against blatant sexism and racism. In [name of university], the majority of students are white and the amount of times I've overheard racist comments and jokes are concerning." - A South Asian, LGBTQ, woman student in their first-year of studying engineering

As part of this need for increased education and awareness women in engineering want their universities to take action to be more inclusive. As we increase diversity in engineering programs we are asking more racialized students to enter traditionally White spaces and this can be harmful [17], [21], [22], [23]. If they are experiencing blatant sexism and racism it is also likely that they are having to cope with even more frequent microaggressions. Our students want action to be taken in response to the racism they experience and create safer spaces for them to learn.

"I feel as though every school has ways to improve how they approach inclusivity, and even by taking small steps such as making sure all students regardless of gender., sexuality and race have access to the same resources, that could be an excellent step in the right direction!' - A White, $L G B T Q$, woman student in biomedical engineering

Universities could also take action to ensure equitable 
access to resources and spaces. Offering a service or resource to all students does not guarantee equitable access. If a student feels that this could be improved, there are likely barriers to access that are going unrecognized.

"I believe there are more supports that could be put in place. For a concrete example, our programs common room is very geared toward male-dominated activities. A group of females, myself included, did bring this issue to the departments attention last year but as of yet no changes have been implemented." - A White, heterosexual, women studying engineering science.

Physical spaces on campus are not always inclusive to everyone. Dominant traditional culture can make these spaces unwelcoming to students who don't see themselves represented here.

When students bring these issues to our attention, it is all of our responsibility to listen, to act and be allies to marginalized students.

\subsection{Women students in engineering still need community}

When the responses were coded four universal needs were identified: the need to be included, to be listened to, to be acknowledged, and to be supported.

Women students need to feel included in engineering education, they need to see themselves represented in their peer groups and in their professors and instructors. In these responses the desire to see other women and other racialized women in their classrooms became clear. While significant work has been done to recruit women into engineering there are still gaps in representation and therefore women still experience a sense of otherness and are not being fully included in the spaces they are beginning to occupy.

Women students in engineering need to be listened to. They need to share their experiences and ideas. They want to talk about the issues they face and more importantly they want to be heard.

Women students in engineering need to be acknowledged. Recognition of diversity and binary gender are not enough. They need their institutions to acknowledge that women continue to be marginalized in engineering despite the increase in the number of women studying engineering. They need this to be acknowledged and actions to be taken to educate others on these issues, create inclusive physical spaces and respond to sexism and racism.

Women students need to be supported. They need to be supported by each other, they need to be supported by their peers, their professors, and their universities. They need supportive spaces where they can connect and find community within engineering spaces. Intersectionality needs to be considered when developing initiatives to support women students to ensure more women are supported.

When considered together, all four of these needs indicate that what women engineering students need and are still looking for is community and belonging in engineering education.

\section{4. "I'm not sure."}

Two respondents did not know what their university could do to provide better support, both responding "I' $m$ not sure." Yet, one respondent indicated that she felt disadvantaged by her identity in another part of the survey.

"I feel like I have to work harder to make sure I am not spoken over and that I my opinions are recognized." - A Southeast Asian, heterosexual, woman, studying industrial engineering.

Again, this speaks to the need to be listened to acknowledged found in other responses and it is likely that this student would also appreciate more education, awareness, and opportunities to connect with peers and educators who are experiencing similar issues.

The other respondent did not know what her institution could do because she had not experienced discrimination herself. This is good. If the goal is to be inclusive for all women then being inclusive for some women can be seen as a sign of progress, however, one out of 15 respondents saying that no change is needed reinforces that there is still a lot of work and change required to make engineering education inclusive for all students.

\section{CONCLUSIONS}

Women in engineering need deeper community connections and a stronger sense of belonging in engineering education. So, what can we as educators do? We can work towards meeting the needs of all women students and be more intentionally intersectional in this work.

Work to include more women in your disciplines at all levels. Be active in advocating for equitable and intersectional recruitment, admission \& hiring practices. Participate on hiring committees and support outreach work in marginalized communities. Advocate for the collection of more demographic data, move beyond thinking only about binary gender and consider more identities for a more intersectional approach to this work.

Listen to women students. Be mindful that the women in your classrooms are not a homogenous group. Their individual identities will impact their experiences in your classroom. Do not assume you know what they need or who they are based on your perception of their identities. Ask them about their experiences, empathize with them, and hear them. If you are able to do so, share aspects of who you are and your experiences with your students so they know that there are people around them who may also 
understand their experiences. Make an active effort to connect with the women in your classrooms, your labs and on your campuses.

Acknowledge that discrimination still exists in engineering education and that this discrimination is experienced differently by different people. Learn about equity, diversity and inclusion issues. Speak up and act against instances of discrimination on campus. Join the CEEA Diversity Special Interest Group to connect with other colleagues doing this work.

Support the creation of identity-based student groups. There are currently only two universities with student chapters of the National Society of Black Engineers (NSBE) in Ontario. More universities have student groups for LGBTQ students and Women in Science \& Engineering (WISE) student chapters but not all. Support students who want to form identity-based groups. Become a faculty advisor for an identity-based student group and/or advocate for funding from your department or Faculty for these groups. You do not need to share the identity of the students in these groups in order to help them advocate for themselves. Not all universities have Black engineering faculty or faculty who are able to be open about their gender identity, sexual orientation or mental health etc., you do not have to wait for someone to be hired to do this work. We can all be active allies.

I hope hearing the ideas from students shared and discussed here will inspire engineering educators to take actions towards "warming up" our campuses for all the women studying engineering in Ontario.

\section{Acknowledgements}

Thank you to the students who shared their insights and experiences with me. Thank you to the Engineering Student Society Council of Ontario, the National Society for Black Engineers, and EngiQueers Canada for helping to promote this research and recruit students to participate. I'd also like to acknowledge the support of my thesis supervisor, Prof. Angela Hildyard as well as my thesis committee members Prof. Carol-Ann Burke and Prof. Stephanie Waterman.

\section{References}

[1] B. R. Sandler, S. A. Silverberg, and R. M. Hall, The chilly classroom climate: A guide to improve the education of women. Washington: National Association for Women in Education, 1996.

[2] "Canadian Engineers for Tomorrow | Engineers Canada." [Online]. Available:

https://engineerscanada.ca/publications/canadianengineers-for-tomorrow-2017\#total-undergraduate-studentenrolment-by-province. [Accessed: 16-Feb-2020].

[3] D. Hardy Cox and C. C. Strange, "Student diversity in Canadian higher education," in Serving diverse students in Canadian higher education, D. Hardy Cox and C. C. Strange, Eds. Montreal \& Kingston: McGill-Queen's
University Press, 2016, pp. 3-12.

[4] J. C. Blickenstaff, "Women and science careers: leaky pipeline or gender filter?," Gend. Educ., vol. 17, no. 4, pp. 369-386, 2005.

[5] V. A. Haines, J. E. Wallace, and M. E. Cannon, "Exploring the gender gap in engineering: A re-specification and test of the hypothesis of cumulative advantages and disadvantages," J. Eng. Educ., vol. 90, no. 4, pp. 677-684, Oct. 2001.

[6] C. Logel, G. M. Walton, S. J. Spencer, E. C. Iserman, W. von Hippel, and A. E. Bell, "Interacting with sexist men triggers social identity threat among female engineers," $J$. Pers. Soc. Psychol., vol. 96, no. 6, pp. 1089-1103, 2007.

[7] B. E. Rincón and C. E. George-Jackson, "Examining department climate for women in engineering: The role of STEM interventions," J. Coll. Stud. Dev., vol. 57, no. 6, pp. 742-747, Sep. 2016.

[8] R. M. Marra, K. A. Rodgers, D. Shen, and B. Bogue, "Women engineering students and self-efficacy: A multiyear, multi-institution study of women engineering student self- efficacy," J. Eng. Educ., vol. 98, no. 1, p. 27, 2009.

[9] C. M. Jagacinski, "Women engineering students: Competence perceptions and achievement goals in the freshman engineering course," Sex Roles, vol. 69, no. 1112, pp. 644-657, Dec. 2013.

[10] C. M. Vogt, D. Hocevar, and L. S. Hagedorn, “A social cognitive construct validation: Determining women's and men's success in engineering programs," J. High. Educ., vol. 78, no. 3, pp. 337-364, May 2007.

[11] G. M. Walton, C. Logel, J. M. Peach, S. J. Spencer, and M. P. Zanna, "Two brief interventions to mitigate a 'chilly climate' transform women's experience, relationships, and achievement in engineering.," J. Educ. Psychol., vol. 107, no. 2, pp. 468-485, 2015.

[12] F. Henry et al., The equity myth: Racialization and Indigeneity at Canadian universities. Vancouver; Toronto: UBC Press, 2017.

[13] A. Y. Davis, Women, race \& class. London: Women's Press, 1982.

[14] P. Hill Collins, Black feminist thought: knowledge, consciousness, and the politics of empowerment, Second edition. New York; London: Routledge, 2009.

[15] bell hooks, Feminism is for everybody: Passionate politics. Cambridge: South End Press, 2000.

[16] B. Smith, Ed., Home girls: a Black feminist anthology. New Brunswick, N.J: Rutgers University Press, 2000.

[17] E. A. Cech and W. R. Rothwell, "LGBTQ Inequality in Engineering Education," J. Eng. Educ., vol. 107, no. 4, pp. 583-610, 2018.

[18] B. E. Hughes, “"Managing by not managing': How gay engineering students manage sexual orientation identity," $J$. Coll. Stud. Dev., vol. 58, no. 3, pp. 385-401, May 2017.

[19] D. L. McCoy, C. L. Luedke, and R. Winkle-Wagner, "Encouraged or weeded out: Perspectives of students of color in the STEM disciplines on faculty interactions," $J$. Coll. Stud. Dev., vol. 58, no. 5, pp. 657-673, 2017.

[20] J. Page-Reeves, A. Marin, M. Moffett, K. DeerInWater, and D. Medin, "Wayfinding as a concept for understanding success among Native Americans in STEM: 'learning how to map through life,"” Cult. Stud. Sci. Educ., Mar. 2018.

[21] E. Atwood and G. R. López, "Let's be critically honest: towards a messier counterstory in critical race theory," Int. 
J. Qual. Stud. Educ., vol. 27, no. 9, pp. 1134-1154, 2014.

[22] D. A. Clark, S. Kleiman, L. B. Spanierman, P. Isaac, and G. Poolokasingham, "'Do you live in a teepee?':

Aboriginal students' experiences with racial microaggressions in Canada," J. Divers. High. Educ., vol. 7, no. 2, pp. 112-125, 2014.

[23] J. M. Grossman and M. V. Porche, "Perceived gender and racial/ethnic barriers to STEM success," Urban Educ., vol. 49, no. 6, pp. 698-727, 2013.

[24] D. W. Sue et al., "Racial Microaggressions in Everyday Life: Implications for Clinical Practice," Am. Psychol., vol. 62, no. 4, pp. 271-286, 2007.

[25] H. K. Ro and K. I. Loya, "The effect of gender and race intersectionality on student learning outcomes in engineering," Rev. High. Educ., vol. 38, no. 3, pp. 359396, Mar. 2015.

[26] K. Crenshaw, "Mapping the margins: Intersectionality, identity politics, and violence against women of color," Stanford Law Rev., vol. 43, no. 6, pp. 1241-1299, 1991.

[27] A.-M. Hancock, "When Multiplication Doesn't Equal Quick Addition: Examining Intersectionality as a Research Paradigm," Perspect. Polit., vol. 5, no. 1, pp. 63-79, 2007. 